\title{
The Effect of Patient Experience on Patient Loyalty through Patient Satisfaction in Telemedicine Application Services During the Covid-19 Pandemic
}

\author{
Dian Eka Permata Sari W ${ }^{1}$, Fridawaty Rivai ${ }^{1}$, Ridwan Amirrudin ${ }^{1}$ \\ ${ }^{1}$ Faculty of Public Health, Hasanuddin University, Indonesia \\ Received: May 25, 2021 \\ Received in Revised: June 21, 2021 \\ Accepted: July 2, 2021
}

\begin{abstract}
The purpose of this research was to investigate the relationship between patient experience and satisfaction and patient loyalty utilizing Halodoc and Alodokter. Direct and indirect impacts between study variables are among the topics that have been investigated. A cross-sectional research approach was employed in this study, which combined quantitative descriptive analysis with an analytic survey. The research included 500 patients who used Halodoc and another 500 individuals who used Alodokter as part of their treatment. The study sample consisted of 286 individuals, including 143 patients who used Halodoc and 143 patients who used Alodokter, who were selected using the proportionate sampling method. An association between patient experience and patient satisfaction was found to be significant ( $\mathrm{p}$-value 0.0000.05), while an association between patient experience and patient loyalty was found to be significant ( $p$-value0.0000.05). As an added bonus, there was a direct relationship between customer happiness and customer loyalty, with a p-value of 0.0000 .05 . The indirect impact of patient experience on patient loyalty and patient satisfaction as a mediator, however, was shown to be statistically significant ( $p$-value $=0.0000 .05$ ) and was found to be significant. This research suggests that telemedicine services are being used more often in health agencies during the COVID-19 pandemic because of the potential advantages it provides, such as its efficiency and the impact it has on patient happiness and loyalty, according to the findings.
\end{abstract}

Keywords: Patient Experience, Patient Satisfaction, Patient Loyalty, Telemedicine

\section{Introduction}

During the COVID-19 epidemic, there has been a rise in the usage of telemedicine in Indonesia. The number of individuals who utilize telemedicine applications has risen from 4 million before the COVID-19 pandemic to 15 million after the COVID-19 pandemic, according to the CDC (Republic of Indonesia Cabinet Secretariat Public Relations, 2020). In January 2020, the Indonesian Association of Internet Service Providers reported that the number of individuals utilizing health apps rose during the COVID-19 epidemic, with 81 percent of people seeking health information and 63 percent consulting with health professionals on the internet.

Telemedicine is a health technology that may be used to handle some of the difficulties that the health-care system is experiencing as a result of global infectious disease epidemics. Telemedicine is becoming more popular. In the face of the present COVID-19 epidemic, telemedicine is being utilized all over the world (Rockwell \& Gilroy, 2020). Aside from that, the Ministry of Health has encouraged hospitals and other health-care institutions to develop and implement telemedicine services in order to provide health-care services to the general population. This is due to the fact that telemedicine is considered to be a cutting-edge method to dealing with the COVID-19 issue.

As a result of the COVID-19 pandemic, the application of the telemedicine system has been focused on reducing and preventing overcrowding in emergency departments, emergency 
clinics, and primary care clinics; direct transmission; and providing reassurance and education to patients about their treatment plans. Additionally, telemedicine may be utilized to meet the continuing health care requirements of patients with chronic diseases, which can result in a reduction in the number of in-person clinic visits. Through the use of telemedicine, exposure between patients and health care professionals may be reduced as well, since health care employees are individuals who are at risk of being a source of COVID-19 transmission owing to their direct interaction with patients who have been infected with COVID-19 (Rockwell \& Gilroy, 2020). According to Smith et al. (2020), telemedicine is being utilized to offer treatment during the COVID-19 pandemic, mainly as a means of minimizing the danger of crosscontamination induced by close contact.

When it comes to health care, the patient experience represents the greatest opportunity. This includes the patient's experience with quality and safety, as well as the moment of service, all of which are influenced by costs and their implications for accessibility and affordability, all of which are influenced by public and population health, as well as health care use decisions (Wolf, 2016). It is becoming more essential to consider the patient experience when evaluating the performance of healthcare organizations and when revamping services to meet the requirements of patients (Gualandi et al., 2019).

According to Liljander and Strandvik (1994), customer or patient satisfaction refers to the inside perspective of the customer or patient about the experience he or she has had in health services where the results will be evaluated based on what the customer or patient has received from the service provider. It is made possible for patient satisfaction to be responsive to the opinions and requirements of patients via continual development of the service quality system, so that the patient experience will have an impact on patient satisfaction and not the other way around (Zeithaml et al., 1996).

The authors of the research, Ieva and Ziliani (2017), claim that patient experience and happiness will have an impact on a customer's willingness to utilize a service again and again. Similarly, Pramita (2019) said that customer experience was the most important element in customer loyalty, and that this was supported by research. A customer experience is the result of a sequence of encounters between a consumer and a product, business, or component of an organization that causes a response in the customer to take place. The experience is genuinely personal and requires participation on many levels (intellectual, emotional, sensory, physical, and spiritual) on the part of the consumer. The purpose of this research is to perform a study entitled "The impact of patient experience on customer loyalty via customer satisfaction in telemedicine services" during the COVID-19 pandemic.

\section{Methods}

This study was performed on users of two Telemedicine apps in Indonesia, namely Alodokter and Halodoc. The participants were asked to complete a survey. With a cross-sectional research design, a quantitative method was utilized in conjunction with analytical questionnaires to conduct the research study. The participants in this research are patients who have utilized telemedicine apps, namely Alodokter and Halodoc, during the COVID-19 pandemic, which will take place between March 2020 and August 2020. The population of this study consisted of 1,000 patients, 500 of whom were recruited via the Halodoc application and 500 of whom were recruited through the Alodokter application. A total of 286 research samples were chosen using the quota sampling technique, which consisted of collecting 143 samples from Halodoc and 143 samples from Alodokter in sequence according to the list of names given by telemedicine service providers, and combining the results. The data were examined using multivariate analytic methods based on structural equation modeling (SEM). In order to determine the direct and indirect impact between variables, the AMOS 16 software was utilized.

Copyright $@$ 2021, Journal of Asian Multicultural Research for Medical and Health Science Study, Under the license CC BY-SA 4.0 


\section{Results and Discussion}

The analysis in this study uses the AMOS Structural Equation Modeling (SEM) analysis technique. The test results using the AMOS SEM are described as follows:

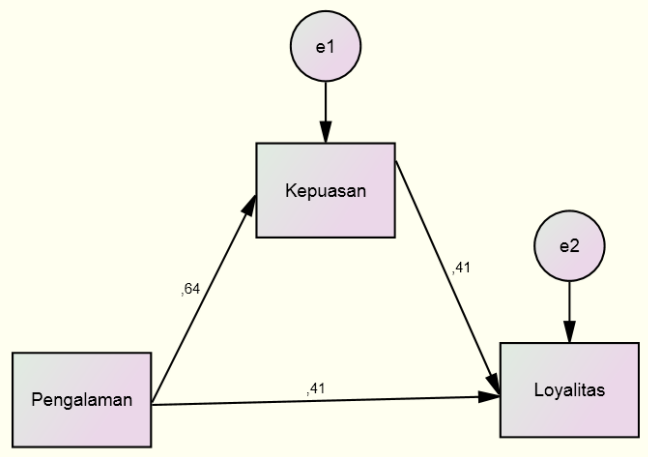

Figure 1. Structural Model with AMOS . SEM

Source: Primary data processed (2021)

The results of the direct effect test are presented in the following table.

Table 1. Direct Effect Hypothesis Test Results

\begin{tabular}{|l|c|c|c|c|}
\hline & Estimate & SE & CR & p \\
\hline Satisfaction <--- Experience & 1.131 & 0.080 & 14,165 & $* * *$ \\
\hline Loyalty <--- Experience & 0.652 & 0.083 & 7,835 & $* * *$ \\
\hline Loyalty <--- Satisfaction & 0.372 & 0.047 & 7,862 & $* * *$ \\
\hline
\end{tabular}

Remarks: $* * * p<0.001$

Source: Primary data processed (2021)

According to the data in the table above, there is a direct relationship between patient experience and patient satisfaction, a direct relationship between patient experience and patient loyalty, and a direct relationship between patient satisfaction and patient loyalty, all of which have a p-value less than 0.05. The magnitude of the influence of each variable is depicted in Figure 5, with the magnitude of the effect of patient experience on patient satisfaction being 64 percent, the magnitude of the direct influence of patient experience on patient loyalty being 41 percent, and the magnitude of the effect of patient satisfaction on patient loyalty being 41 percent.

Table 2. Direct Effect Hypothesis Test Results

\begin{tabular}{|l|c|c|c|c|}
\hline & Estimate & SE & CR & p \\
\hline Satisfaction $<---$ Experience & 1.131 & 0.080 & 14,165 & $* * *$ \\
\hline Loyalty <--- Experience & 0.652 & 0.083 & 7,835 & $* * *$ \\
\hline Loyalty <--- Satisfaction & 0.372 & 0.047 & 7,862 & $* * *$ \\
\hline Remarks: $* * * \mathrm{p}<0.001$
\end{tabular}

Source: Primary data processed (2021)

According to the data in the table above, there is a direct relationship between patient experience and patient satisfaction, a direct relationship between patient experience and patient loyalty, and a direct relationship between patient satisfaction and patient loyalty, all with a pvalue less than 0.05. As indicated in Figure 5, the size of the impact of each variable is 64 percent for patient experience, 41 percent for direct influence of patient experience on patient loyalty, and 41 percent for the magnitude of the effect of patient satisfaction on patient loyalty.

Copyright (O) 2021, Journal of Asian Multicultural Research for Medical and Health Science Study, Under the license CC BY-SA 4.0 
Table 3. The Magnitude of the Effect of Mediation with the Sobel Test

Indirect effect(s) of $\mathrm{X}$ on $\mathrm{Y}$ :

Effect BootSE BootLLCI BootULCI

M .1692.0278 .1140.2226

Completely standardized indirect effect(s) of $\mathrm{X}$ on $\mathrm{Y}$ :

Effect BootSE BootLLCI BootULCI

M .2829.0449.1938.3664

The table above demonstrates that the range of BootLLCI and BootULCI values does not contain a value of 0 (zero) when considering the indirect impact of $X$ on $Y$. This is due to the fact that the range of BootLLCI and BootULCI values is not zero. As a result, it is possible to conclude that the estimates is substantial and that a mediation effect exists. Thus, there was a statistically significant indirect relationship between experience and patient loyalty, as measured by patient satisfaction. The indirect impact/mediating effect of patient experience on patient loyalty has a magnitude of 0.2829 or 28.29 percent, and it is a positive effect.

\section{The Direct Effect of Patient Experience on Patient Satisfaction in Telemedicine Services during the COVID-19 Pandemic.}

Patients' experiences with telemedicine application services during the COVID-19 pandemic had a direct impact on patient satisfaction, according to the findings of the study, which was 64 percent. This implies that the more positive a person's experience is with telemedicine application services, the greater the likelihood that the patient will be satisfied with the application. The findings also indicate that the impact of patient experience on patient satisfaction is 64 percent, which implies that 64 percent of patient satisfaction is driven by patient experience, with the remaining 36 percent determined by other variables, according to the findings.

These findings are consistent with the findings of Orlando et al. (2019), Imlach et al. (2021), and Polinski et al. (2016), who found that the patient experience had an impact on patient satisfaction while utilizing Telemedicine. According to Imlach et al. (2021), patient satisfaction with the use of telemedicine is high because the use of telemedicine may offer adequate time for consultation and patients can pay close attention to what physicians are saying during the consultation. These findings are related to the satisfaction of social requirements of patients in the establishment of contact with physicians in the context of telemedicine health care. As long as the user has a good experience and perceives the advantages of the service, the degree of user satisfaction with the service has a positive impact and has the potential to influence the long-term sustainability of interest in the service. It is possible to gauge customer satisfaction based on the quality of the information supplied (Zagita et. al., 2019).

\section{The Direct Effect of Patient Experience on Patient Loyalty in Using Telemedicine Applications during the COVID-19 Pandemic}

The findings revealed that patient satisfaction had a significant impact on patient loyalty to telemedicine application services during the COVID-19 pandemic, with patient satisfaction accounting for about $41 \%$ of patient loyalty. As a result, the more positive a person's experience with telemedicine application services is, the more likely it is that they will be able to build patient loyalty to the application in the future. It also shows the size of the impact of patient experience on patient loyalty, which is 41 percent, which indicates that patient experience determines 41 percent of patient loyalty, with the remaining $59 \%$ driven by other variables.

These findings are consistent with the findings of Ieva and Ziliani (2017), who found that patient experience and satisfaction had an impact on customer loyalty and the likelihood of 
returning for further treatments. Similarly, Pramita (2019) said that customer experience was the most important element in customer loyalty, and that this was supported by research. Patient happiness and loyalty may be predicted by experience in the form of a pleasant medical environment, effective communication, and the protection of personal information and security (Liu, et al., 2021). Customers' perceptions of the quality of their experiences are extremely strongly linked to their objectives, according to Lemke et al. (2010). They also consider the superiority or inferiority of their experiences to be very directly related to their aims (Senjaya et al., 2013).

\section{The Direct Effect of Patient Satisfaction on Patient Loyalty in Using Telemedicine Applications during the COVID-19 Pandemic}

According to the findings of the research, there was a clear relationship between patient satisfaction and patient loyalty in telemedicine application services during the COVID-19 pandemic, with a correlation of about $41 \%$ between the two. Therefore, the greater the level of patient satisfaction with telemedicine, the greater the likelihood of increased patient loyalty. Patients' happiness accounts for $41 \%$ of their loyalty, with the remaining $59 \%$ influenced by other variables.

Patients' happiness, according to Liu et al. (2021), may contribute to the development of patient loyalty and has a direct connection with patient loyalty. The findings of this study corroborate the findings of a study conducted by Ieva and Ziliani (2017), which found that patient experience and satisfaction had an impact on consumers' willingness to return for more services. Additionally, the findings of this study are comparable to the findings of a study conducted by Tosyali et al., (2019), which found that patient satisfaction has a favorable and substantial impact on patient loyalty. It is the findings of this research that provide credence to Pramita's (2019) conclusion that the higher the degree of pleasure felt by service consumers, the greater the amount of loyalty.

Ramli (2017) explains that patient happiness has a significant impact on patient loyalty when it comes to the usage of telemedicine apps, and that patient satisfaction is an essential factor to consider while using telemedicine applications. In health care, patient satisfaction is a measure of how pleased a patient is with the health treatment that he or she has gotten from a health care provider. Patients' loyalty is also influenced by their level of satisfaction with the hospital, as well as the institution's overall reputation, which has both a positive and substantial effect on patient loyalty.

\section{Indirect Effect of Patient Experience on Patient Loyalty with Patient Satisfaction as Mediator}

The findings revealed that patient experience had an indirect impact on patient loyalty via patient satisfaction, which was shown in the study. Given the size of the impact, it is reasonable to assume that 28.29 percent of patient satisfaction is a mediating effect of the relationship between patient experience and patient loyalty. As previously reported by Kamath et al. (2019), the results support the notion that the impact of customer experience on customer loyalty happens both directly and indirectly via mediation and moderating effects. Customer happiness, it is said, acts as a mediating factor between the impact of the customer experience and the influence of customer loyalty.

Patient satisfaction was shown to be a partial mediator of patient-centered treatment and experience, according to a study published by Thomas et al. (2017). It is becoming more essential to consider the patient experience when evaluating the performance of healthcare organizations and when revamping services to meet the requirements of patients (Gualandi et al., 2019) 


\section{Conclusion}

According to the findings of the study, it can be stated that: (1) There was a direct correlation between patient experience and patient satisfaction in telemedicine application services during the COVID-19 pandemic, with a 64 percent correlation between the two. (2) There was a direct influence between patient experience and patient loyalty to telemedicine application services during the COVID-19 pandemic of 41 percent; (3) There was a direct influence between patient satisfaction and patient loyalty in telemedicine application services during the COVID-19 pandemic of 41 percent; (4) There was an indirect effect / mediating effect between patient experience and patient loyalty in telemedicine application services during the COVID-19 pandemic of 41 percent; (5) There was a direct influence between patient satisfaction and It is possible for patients to conduct health consultations through the telemedicine application in order to reduce contact and maintain distance during the COVID-19 pandemic, and telemedicine service providers should always strive to improve the quality of services and information they offer their patients.

\section{References}

Gualandi, R., Masella, C., Viglione, D., Tartaglini, D. (2019). Exploring the hospital patient journey: What does the patient experience? PLOS ONE. 14(12): e0224899

Humas Sekretariat Kabinet Republik Indonesia (2020). Presiden Apresiasi Penggunaan Aplikasi 'Telemedicine' untuk Kurangi Risiko Tenaga Medis. Diakses di https://setkab.go.id/presiden-apresiasi-penggunaan-aplikasi-telemedicine-untukkurangi-risiko-tenaga-medis/.

Ieva, M. dan Ziliani, C. (2017). Customer experience in retail banking: what touchpoints matter for customer loyalty? Conference: European Association for Education and Research in Commercial Distribution At: Dublin Juli 2017.

Imlach, F., McKinlay, E., Kennedy, J., Pledger, M., Middleton, L., Cumming, J., \& McBrideHenry, K. (2021). Seeking healthcare during lockdown: challenges, opportunities and lessons for the future. International Journal of Health Policy and Management.

Kamath, P.R., Pai, Y.P. and Prabhu, N.K.P. (2019). Building customer loyalty in retail banking: a serial-mediation approach. International Journal of Bank Marketing, 38(2): 456-484.

Lemke, F., Clark, M., \& Wilson, H. (2011). Customer experience quality: an exploration in business and consumer contexts using repertory grid technique. Journal of the academy of marketing science, 39(6), 846-869.

Liljander, V. dan Strandvik, T. (1994). Estimating Zones of Tolerance in Perceived Service Quality. International Journal of Service Industry Management. 4(2): 6-28.

Liu, S., Li, G., Liu, N., \& Hongwei, W. (2021). The Impact of Patient Satisfaction on Patient Loyalty with the Mediating Effect of Patient Trust. INQUIRY: The Journal of Health Care Organization, Provision, and Financing, 58, 00469580211007221.

Orlando, J.F., Beard, M., dan Kumar, S. (2019). Systematic review of patient and caregivers' satisfaction with telehealth videoconferencing as a mode of service delivery in managing patients' health. PLOS ONE. 14(8): e0221848.

Polinski, J. M., Barker, T., Gagliano, N., Sussman, A., Brennan, T. A., \& Shrank, W. H. (2016). Patients' satisfaction with and preference for telehealth visits. Journal of general internal medicine, 31(3), 269-275. 
Pramita, P.E.G. (2019). Effect Of Experience In Building Satisfaction, Trust And Loyalty. Journal of Applied Management. 17(1): 76-80.

Ramli, A.H. (2017). Patient Satisfaction, Hospital Image and Patient Loyalty in West Sulawesi Province. Business and Entrepreneurial Review. 17(1): 1-14.

Rockwell, L., dan Gilroy, A.S. (2020). Incorporating Telemedicine as Part of COVID-19 Outbreak Response Systems. Am J Manag Care. 26(4):147-148.

Senjaya, V. (2013). Pengaruh customer experience quality terhadap customer satisfaction \& customer loyalty di kafe excelso tunjungan plaza surabaya: perspektif b2c. Jurnal Strategi Pemasaran, 1(1).

Smith, A.C., Snoswell, C.L., Thomas, E., Clemensen, J., Haydon, H., Mehrotra, A., dan Caffery, L.J. (2020). Telehealth for global emergencies: Implications for coronavirus disease 2019 (COVID-19). Journal of Telemedicine and Telecare. 0(0): 1-5

Thomas, S., Quirk, L., Blevins, C., Quatrara, B., \& Letzkus, L. (2017). Incongruence in perceptions: identifying barriers to patient satisfaction in the intensive care unit. Dimensions of Critical Care Nursing, 36(6), 349-354.

Tosyali, H., Sutcu, C.S., dan Tosyali, F. (2019). Patient Loyalty in the Hospital Patient Relationship: The Mediating Role of Social Media. Ocak. 6(1): 783-804.

Wolf, J.A. (2016). Patient experience: Driving outcomes at the heart of healthcare. Patient Experience Journal. 3(1).

Zagita, T. C., Handayani, P. W., \& Budi, N. F. A. (2019). Analysis of Factors Affecting the Loyalty of Using Online Health Services : Case Study of Alodokter. 279-284.

Zeithaml, V.A., Berry, L.L., dan Parasuraman, A. (1996). The behavioral consequences of service quality. Journal of Marketing. 60(April): 31-46 